\title{
Verrucous carcinoma arising from actinic keratosis: a case report
}

\author{
Ji Hyuk Jung ${ }^{1}$, \\ Yeo Reum Jeon ${ }^{1}$, \\ Hyo In Kim ${ }^{1}$, \\ Mi Kyung Lee', \\ Seum Chung ${ }^{1}$ \\ Departments of ${ }^{1}$ Plastic and \\ Reconstructive Surgery and ${ }^{2}$ Pathology, \\ National Health Insurance Service Ilsan \\ Hospital, Goyang, Korea
}

\begin{abstract}
Verrucous carcinoma (VC) is a rare subtype of squamous cell carcinoma that commonly occurs in the oral cavity. However, VC of the facial skin is relatively rare. We report a case of a 91-year-old woman with VC of the facial skin in the left zygoma area. She was diagnosed with actinic keratosis $(4 \times 3 \mathrm{~cm})$ of the same site approximately 12 years previously, but declined further treatment. The mass was excised with a minimum of $0.4 \mathrm{~cm}$ from gross margins with the result of free from tumor of all margins by frozen section, allowing for primary closure after skin undermining. Basal resection was performed in the preplatysmal plane. The diagnosis of VC was confirmed by histopathological examination. Postoperatively, the wound healed without incident and with no signs of facial nerve injury. To our knowledge, this is the first reported case of $\mathrm{VC}$ of facial skin arising from actinic keratosis.
\end{abstract}

Abbreviations: AK, actinic keratosis; HPV, human papillomavirus; SCC, squamous cell carcinoma; UV, ultraviolet; VC, verrucous carcinoma

Keywords: Actinic keratosis / Case reports / Face / Skin / Squamous cell carcinoma / Verrucous carcinoma

\section{INTRODUCTION}

Verrucous carcinoma (VC) is a relatively rare subtype of squamous cell carcinoma (SCC), which was first described by Ackermann in 1948 [1]. The types of skin cancer are classified into basal cell carcinoma, SCC, malignant melanoma, and others (adenocarcinoma, angiosarcoma, extramammary Paget disease, Merkel cell carcinoma, and VC). VC is known as a relatively rare subtype [2]. Chewing tobacco, poor oral hygiene, human papillomavirus (HPV), and habitual smoking are considered significant etiologic factors for VC [3,4]. VC is generally characterized by a grossly ulcerating, fungating, or polypoid wart-

\footnotetext{
Correspondence: Seum Chung

Department of Plastic and Reconstructive Surgery, National Health Insurance

Service Ilsan Hospital, 100 Ilsan-ro, Ilsandong-gu, Goyang 10444, Korea

E-mail: schung@nhimc.or.kr

This study was presented as a poster at the 9th R\&R Forum on May 9-10, 2019 at Chonnam National University, Gwangju, Korea.

Received October 22, 2021 / Revised November 10, 2021 / Accepted December 9, 2021
}

like mass; histologically, the tumors are composed of squamous epithelial cells with minimal cellular atypia arranged in a verrucous pattern [5]. VC can be locally destructive requiring free flap reconstruction [6]. The prognosis of $\mathrm{VC}$ is better than that of SCC since metastasis is extremely rare [3]. Previously, many types of VCs were diagnosed, with the majority occurring in the mucosal tissue. Some VC subtypes of the skin have been reported in the genital/perianal region, toes, and calcaneal regions; thus, most of these cases were located in regions that were protected from sunlight by clothing. Here, we report a case of VC arising from the skin of the cheek with untreated actinic keratosis (AK).

\section{CASE REPORT}

A 91-year-old woman presented with a $5 \times 4 \mathrm{~cm}$ fungating mass that had developed approximately 2 years ago in the left zygoma area (Fig. 1). She had received a histological diagnosis of 


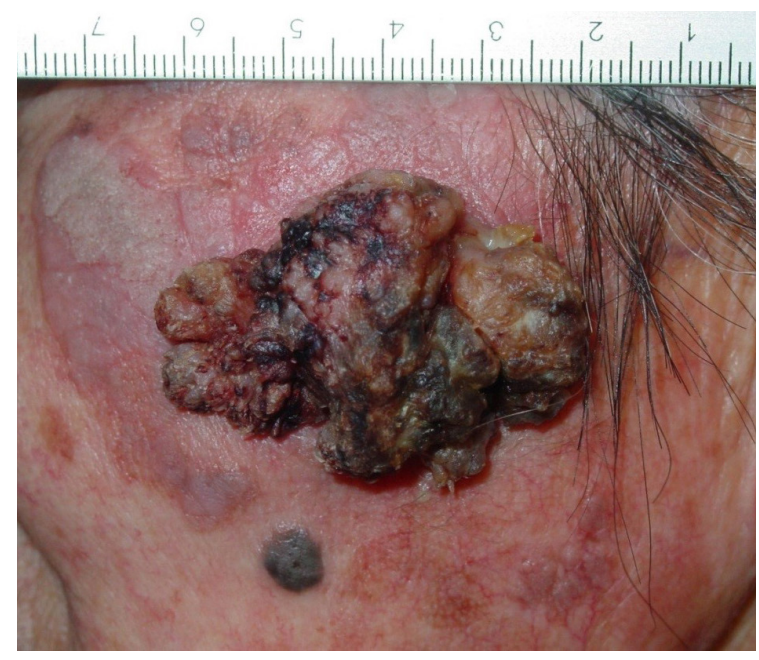

Fig. 1. Preoperative photograph of a 91-year-old woman with a protruding mass on the left zygomatic area.

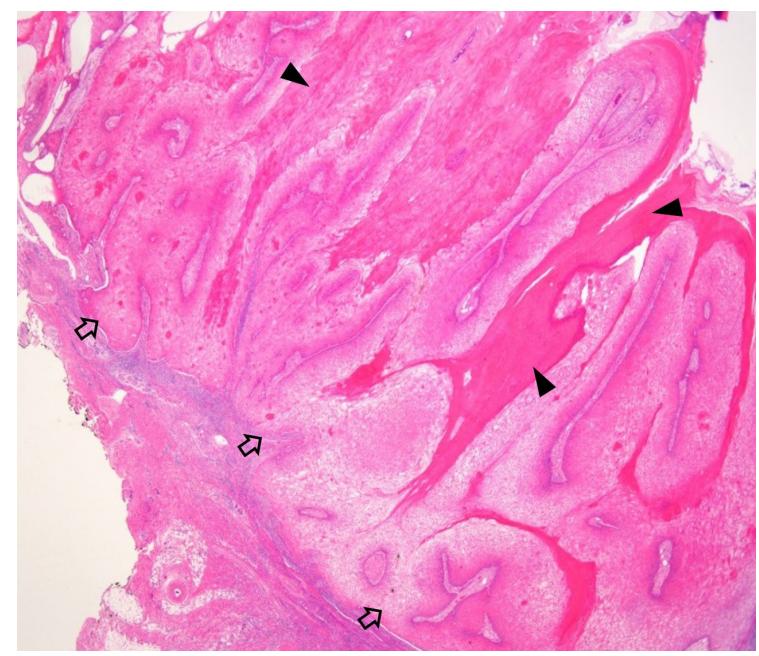

Fig. 2. Verrucous epidermal proliferation (open arrows) with marked hyperkeratosis (arrowheads) (H\&E, $\times 40)$.

AK (mass size at biopsy: $4 \times 3 \mathrm{~cm}$ ) of the same site by punch biopsy approximately 12 years previously but had declined additional treatment after biopsy. A high probability of skin cancer was suspected; therefore, excision of the mass and surrounding AK was recommended. However, the patient refused extensive surgery and only wanted "removal of the protruding mass." An excisional biopsy of the main mass was performed under local anesthesia. The mass was excised with a minimum of $0.4 \mathrm{~cm}$ from gross margins with the result of free from tumor of all margins by frozen section, allowing for primary closure after skin undermining. Basal resection was performed in the preplatysmal plane. The histology showed verrucous epidermal proliferation with marked hyperkeratosis (Fig. 2), and lack of nuclear atypia and stromal infiltration consistent with VC (Fig 3). All surgical margins were free of cancer. Evidence for HPV

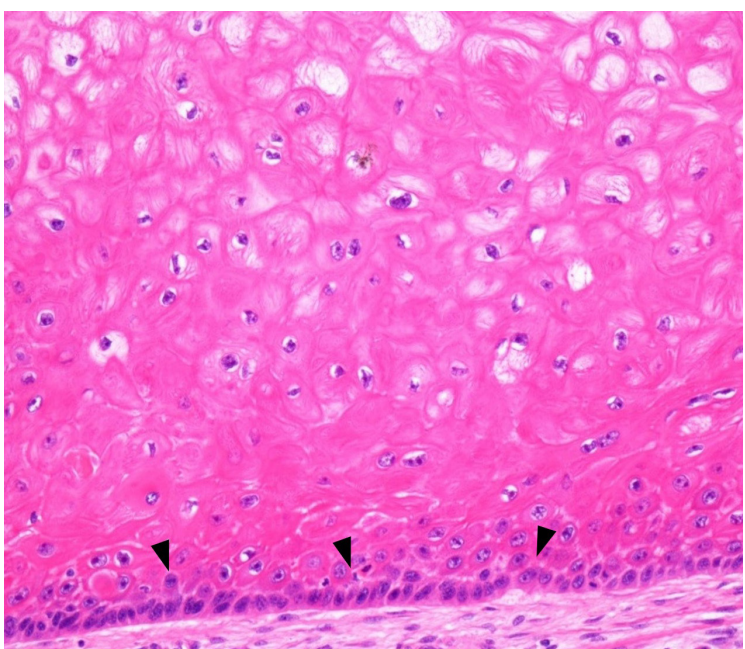

Fig. 3. Lack of nuclear atypia and stromal infiltration (arrowheads) $(\mathrm{H} \& \mathrm{E}, \times 200)$.

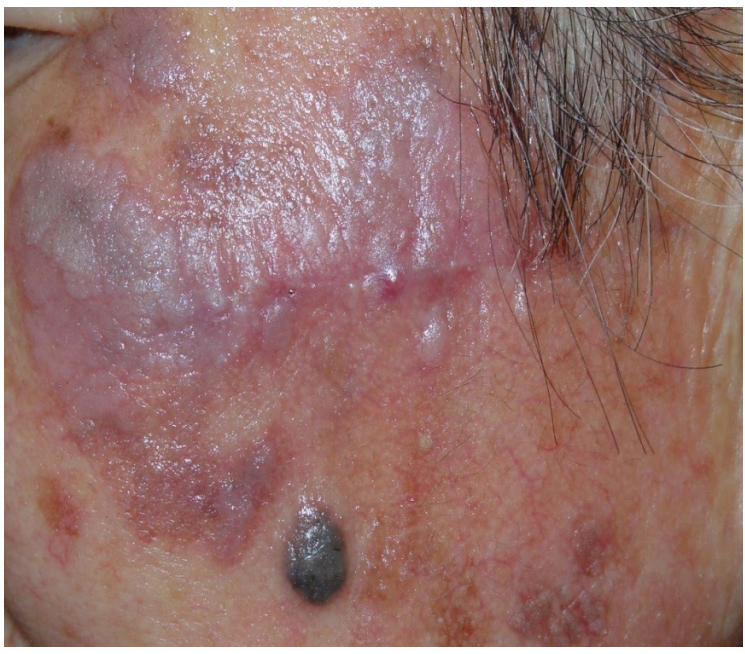

Fig. 4. Postoperative photograph 4 weeks after excision with remaining actinic keratosis.

infection, such as viral inclusion bodies, was not observed. Postoperatively, the wound healed without incident and with no signs of facial nerve injury (Fig. 4).

\section{DISCUSSION}

VC is a low-grade, well-differentiated SCC and extremely rare $(0.075$ per 100,000) [7]. Many types of VC according to the site of occurrence have been reported, such as the genital tract (Buschke-Loewenstein tumor), oral cavity and aerodigestive tract (Ackerman tumor, oral florid papillomatosis, oral florid verrucosis, giant mucocutaneous papillomatosis, nonmetastasizing papillomatosis), palmoplantar area (epithelioma cuniculatum, carcinoma cuniculatum), and cutaneous region (papillomatosis cutis carcinoides, papillomatosis cutis, giant cutane- 
ous papilloma) [8]. Diaz-Perez et al. [9] reported a VC of the lip and several cases of $\mathrm{VC}$ of the lip mucosa and skin regions generally protected from sunlight by clothing (sole, genital area, etc.) have also been reported [10]. However, VC of sun-exposed facial skin is extremely rare $[11,12]$, and to our knowledge, this is the first reported case of $\mathrm{VC}$ of facial skin arising from $\mathrm{AK}$. This case initially presented about 12 years ago with a pruritic mass on the left zygoma of about 1-year duration. The mass was irregularly shaped, elevated and flesh colored. Punch biopsies were done from multiple sites and all showed parakeratosis, atypia of the basilar layer of the epidermis, and mild dermal lymphocytic infiltrate; consistent for $\mathrm{AK}$. The patient was a farmer for more than 60 years who occasionally wore a hat but never used sunscreens for her face or other sun-exposed areas. Since she declined further treatment for her AK even after the possibility of progression to skin cancer was explained, we strongly recommended her to avoid direct sun exposure and to use sunscreen and a hat. However, during her latest presentation it was noted that she had returned to farming soon after her biopsies and only wore a hat.

The etiology of VC is not well known. Chronic inflammatory processes such as osteomyelitis scars, fistulas, ulcers, and lipoidica necrobiosis may be related to the occurrence of VC [13]. Repeated microtrauma and viral infections (especially HPV-6 and HPV-11) are also considered causative factors [14]. However, in this case, evidence of HPV infection such as viral inclusion bodies was not observed, and had no previous history of infection or trauma to the tumor area. This case suggests that the intraepidermal dysplasia characteristic of AK may progress to VC through the three stages of photocarcinogenesis: initiation (ultraviolet [UV]-light exposure, DNA damage), promotion (clonal expansion of metaplastic cells, additional UV irradiation), and progression into neoplastic cells [15]. To our knowledge, this is the first reported case of VC of facial skin arising from $\mathrm{AK}$.

\section{NOTES}

\section{Conflict of interest}

No potential conflict of interest relevant to this article was reported.

\section{Ethical approval}

The study was approved by the Institutional Review Board of National Insurance Service Ilsan Hospital (IRB No. 2021-09-038).

\section{Patient consent}

The patient provided written informed consent for the publica- tion and the use of her images.

\section{ORCID}

Ji Hyuk Jung https://orcid.org/0000-0002-8556-3413

Yeo Reum Jeon https://orcid.org/0000-0002-3435-753X

Hyo In Kim

Mi Kyung Lee https://orcid.org/0000-0003-0640-5597

Seum Chung https://orcid.org/0000-0002-1716-5843 https://orcid.org/0000-0003-3273-6787

\section{Author contribution}

Conceptualization: Seum Chung. Project administration: Seum Chung. Visualization: Ji Hyuk Jung, Mi Kyung Lee. Writing original draft: Ji Hyuk Jung. Writing - review \& editing: Ji Hyuk Jung, Yeo Reum Jeon, Hyo In Kim, Seum Chung. Supervision: Seum Chung.

\section{REFERENCES}

1. Ackerman LV. Verrucous carcinoma of the oral cavity. Surgery 1948;23:670-8.

2. Park YJ, Kwon GH, Kim JO, Kim NK, Ryu WS, Lee KS. A retrospective study of changes in skin cancer characteristics over 11 years. Arch Craniofac Surg 2020;21:87-91.

3. Grossman D, Leffell DJ. Squamous cell carcinoma. In: Freedberg IM, Eisen AZ, Wolff K, Austen KF, Goldsmith LA, Katz SI, editors. Fitzpatrick's dermatology in general medicine. 6th ed. New York: McGraw-Hill; 2003. p. 742-3.

4. Han SH, Kim SH, Kim CK, Jo DI. Multiple nonmelanocytic skin cancers in multiple regions. Arch Craniofac Surg 2020;21: 188-92.

5. Terada T. Verrucous carcinoma of the skin: aa report on 5 Japanese cases. Ann Diagn Pathol 2011;15:175-80.

6. Suh JM, Chung CH, Chang YJ. Head and neck reconstruction using free flaps: a 30-year medical record review. Arch Craniofac Surg 2021;22:38-44.

7. Wang N, Huang M, Lv H. Head and neck verrucous carcinoma: a population-based analysis of incidence, treatment, and prognosis. Medicine (Baltimore) 2020;99:e18660.

8. Schwartz RA. Verrucous carcinoma of the skin and mucosa. J Am Acad Dermatol 1995;32:1-21.

9. Diaz-Perez JL, Moreno J, Burgos J. Ackerman's verrucous carcinoma on the lower lip. Med Cutan Ibero Lat Am 1981;9:10510.

10. Chaudhary S, Bansal C, Ranga U. Verrucous carcinoma of the buccal mucosa with extension to the cheek. Cutis 2017;99:E168.

11. Nguyen KQ, McMarlin SL. Verrucous carcinoma of the face. Arch Dermatol 1984;120:383-5. 
12. Patrascu V, Enache O, Ciurea R. Verrucous carcinoma: observations on 4 cases. Curr Health Sci J 2016;42:102-10.

13. Depprich RA, Handschel JG, Fritzemeier CU, Engers R, Kubler NR. Hybrid verrucous carcinoma of the oral cavity: a challenge for the clinician and the pathologist. Oral Oncol Extra 2006;42: 85-90.
14. Martin F, Dalac S, Lambert D. Verrucous carcinoma. Nosologic aspects, apropos of 4 cases. Ann Dermatol Venereol 1995; 122:399-403.

15. Elmets CA. Cutaneous photo carcinogenesis. In: Mukhtar H, editor. Pharmacology of the skin. Boca Raton: CRC Press; 1992. p. 389-416. 